\begin{tabular}{|c|l|}
\hline Title & $\begin{array}{l}\text { Three dimensionally ordered macroporous mixed iron oxide; Preparation and structural characterization of inverse } \\
\text { opals with skeleton structure }\end{array}$ \\
\hline Author(s) & Sadakane, Masahiro; Takahashi, Chigusa; Kato, Nobuy asu; A sanuma, Takahito; Ogihara, Hitoshi; Ueda, W ataru \\
\hline Citation & $\begin{array}{l}\text { Chemistry letters, 35(5), 480-481 } \\
\text { https://doi.org/10.1246/1.2006.480 }\end{array}$ \\
\hline Issue Date & 2006-05-05 \\
\hline Doc URL & http://hdl.handle.net/2115/14630 \\
\hline Rights & copyright(c)2006 The Chemical Society of Japan \\
\hline Type & article (author version) \\
\hline File Information & FinalManuscriptCL 060149-1.pdf \\
\hline
\end{tabular}

Instructions for use 


\title{
Three Dimensionally Ordered Macroporous Mixed Iron Oxide; Preparation and Structural Characterization of Inverse Opals with Skeleton Structure
}

\author{
Masahiro Sadakane,* Chigusa Takahashi, Nobuyasu Kato, Takahito Asanuma, Hitoshi Ogihara, and Wataru Ueda \\ Catalysis Research Center, Hokkaido University, N-21, W-10, Sapporo, 001-0021
}

(Received February 2, 2006; CL-060149; E-mail: sadakane@cat.hokudai.ac.jp)

Three dimensionally ordered macroporous (3DOM) materials of polycrystalline spinel- and perovskite-type mixed metal oxide $\left(\mathrm{ZnFe}_{2} \mathrm{O}_{4}, \mathrm{NiFe}_{2} \mathrm{O}_{4}\right.$, and $\left.\mathrm{LaFeO}_{3}\right)$ could be successfully fabricated using colloidal crystal template method in excellent yield. More than $90 \%$ of the obtained materials had the 3DOM structure. The crystallites of the spinel- or perovskite-type mixed iron oxide construct struts, tetrahedral and square prism vertexes. The struts connect the tetrahedral and square prism vertexes to produce inverse opals with skeleton structure in three-dimensions.

Recently, three-dimensionally ordered macroporous (3DOM) materials with pores sized in the sub-micrometer range have become the focus of studies because of their application in photonic crystal, catalysis, and separation. ${ }^{1}$ To date, most of the 3DOM materials have been synthesized by colloidal crystal template methods as follows: (i) a colloidal crystal template is prepared by ordering mono-disperse spheres [e.g., polystyrene (PS) or poly(methyl methacrylate) (PMMA)] into a face-centered cubic close-packed array (opal structure); (ii) interstices in the colloidal crystal are then filled with raw materials, which is solidified to an intermediate composite structure; and (iii) an ordered form (inverse opals) is produced after removing the template by calcination. Three kinds of inverse opal structures have been reported, so-called "residual volume structure," "shell structure,” and "skeleton structure”. (a)

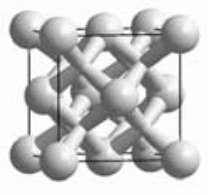

(c)

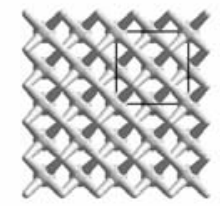

(b)

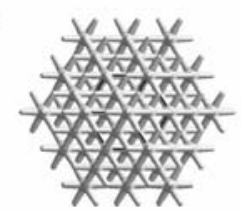

(d)

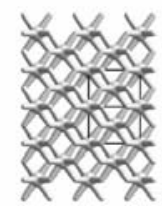

Figure 1. Model of the inverse opals with skeleton structure: (a) cubic unit cell with a lattice constant $a$; (b) view towards (111) plane; (c) view towards (100) plane; (d) view towards (110) plane. In the model, the diameter of the tetrahedral and square prism vertexes was $0.12 \mathrm{a}$ and $0.31 \mathrm{a}$, respectively, using Diamond Version 3.1a (copyright Crystal Impact GbR).

The skeleton structure consists of struts-like bonds and vertexes, the struts connected vertexes in the former octahedral and tetrahedral voids of the opal structure. These struts and vertexes form a $\mathrm{CaF}_{2}$ lattice, where 8-coordinated square prism calcium (the former octahedral voids of the opal) vertex is bigger than tetrahedral fluorine (the former tetrahedral voids of the opal) vertex. ${ }^{3}$ Models of the skeleton structure were depicted in Figure 1. The views towards (111), (100), and (110) plane of the skeleton structure present hexagonal, square, and lozenge arrangement, respectively, as shown in the Figures 1b-1d.

In this paper, we would like to present the well-ordered inverse opals of polycrystalline mixed iron oxide $\left(\mathrm{LaFeO}_{3}\right.$, $\mathrm{ZnFe}_{2} \mathrm{O}_{4}$, and $\mathrm{NiFe}_{2} \mathrm{O}_{4}$ ) with skeleton structure for the first time. This is the first report that both the tetragonal and square prism vertexes are successfully visible. Furthermore, we have achieved to produce the skeleton structure of variety of mixed metal oxide with controlled metal ratio. To date, only the skeleton structures of mono-metal oxides and mono-metals have been seen in the papers, ${ }^{2,7}$ because it has been difficult to produce mixed metal oxides with controlled metal ratio using common 3DOM preparation methods. ${ }^{5,8,9}$

The PMMA colloidal crystals (diameter: $291 \pm 8 \mathrm{~nm}$ ) was prepared by centrifugation (2500 rpm, $1160 \mathrm{G}$ ) of home-made colloidal suspension (ca. $10 \mathrm{~g}$ ) for $24 \mathrm{~h}$. The obtained template was crushed with an agate mortar and the obtained particles were adjusted into $0.425-2.000 \mathrm{~mm}$ using testing sieves (Tokyo Screen, Co. LTD.). The PMMA colloidal crystals were soaked in the ethyleneglycol-methanol solution of the metal nitrates mixture (total metal concentration: $2 \mathrm{M}$ ) for $4 \mathrm{~h}$. Excess solution was removed from the impregnated PMMA colloidal crystals by vacuum filtration. The obtained sample was allowed to dry in air at room temperature overnight. A 0.5 g amount of the sample was mixed with $2.5 \mathrm{~g}$ of quartz sands (10-15 mesh) and calcined in a tubular furnace (i. d. ca. 12 $\mathrm{mm})$ in an air flow $\left(50 \mathrm{~mL} \cdot \mathrm{min}^{-1}\right)$. The temperature was raised at a rate of $1 \mathrm{~K} \cdot \mathrm{min}^{-1}$ to $873 \mathrm{~K}$ and held for $5 \mathrm{~h}$.

Table 1. Physicochemical properties of the samples

\begin{tabular}{cccc} 
Sample & $\begin{array}{c}\text { Crystal system } \\
\text { Lattice constant } / \AA^{\mathrm{a}}\end{array}$ & $\begin{array}{c}\text { Crystallite } \\
\text { size } / \mathrm{nm}^{\mathrm{b}}\end{array}$ & $\begin{array}{c}\text { Pore size } \\
/ \mathrm{nm}^{\mathrm{c}}\end{array}$ \\
\hline $\mathrm{ZnFe}_{2} \mathrm{O}_{4}$ & $\begin{array}{c}\text { Cubic } \\
a=8.447(8.441)^{\mathrm{d}}\end{array}$ & 23 & $183 \pm 4$ \\
$\mathrm{NiFe}_{2} \mathrm{O}_{4}$ & $\begin{array}{c}\text { Cubic } \\
\end{array}$ & 17 & $169 \pm 2$ \\
$\mathrm{LaFeO}_{3}$ & $\begin{array}{c}a=8.332(8.339)^{\mathrm{d}} \\
\text { Orthorombic }\end{array}$ & 25 & $198 \pm 3$ \\
& $\begin{array}{c}a=5.570(5.567)^{\mathrm{d}} \\
b=7.848(7.855)^{\mathrm{d}}\end{array}$ & & \\
& $c=5.552(5.553)^{\mathrm{d}}$ & & \\
\hline
\end{tabular}

${ }^{\mathrm{a}}$ Lattice constants were calculated from XRD data using a least square method.

${ }^{\text {b }}$ Crystallite sizes were calculated by Scherrer's equation from XRD data.

${ }^{\mathrm{c}}$ Pore sizes were estimated from TEM images.

${ }^{\mathrm{d}}$ Values in parentheses were reported value in the JCPDS data.

The crystal structure (spinel and perovskite-type) of the obtained samples was confirmed by XRD measurement (Figure S1 in ESI) with reference to JCPDS data bank 22-1012, 
10-0325, and 37-1493 for $\mathrm{ZnFe}_{2} \mathrm{O}_{4}, \mathrm{NiFe}_{2} \mathrm{O}_{4}$, and $\mathrm{LaFeO}_{3}$, respectively. The cell parameters were quite equal to the reported value (Table 1). Furthermore, any byproducts could not be detected, indicating that the desired mixed iron oxide was successfully obtained.

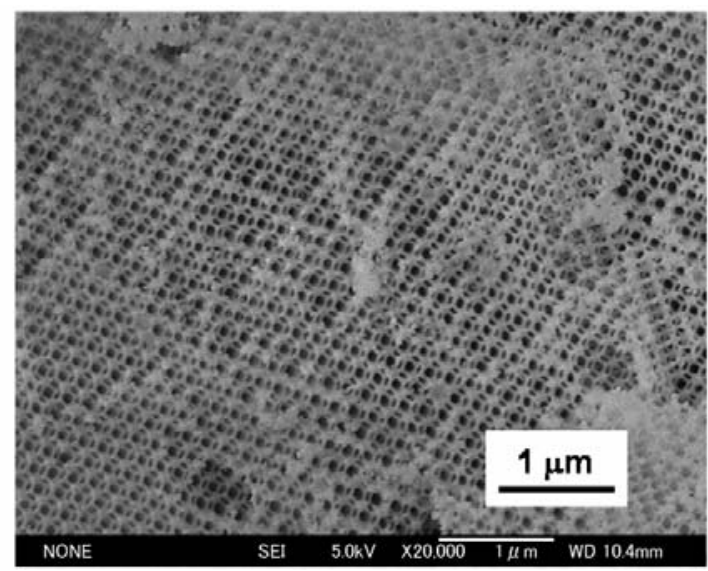

Figure 2. SEM images of the $\mathrm{LaFeO}_{3}$ material of a particle.
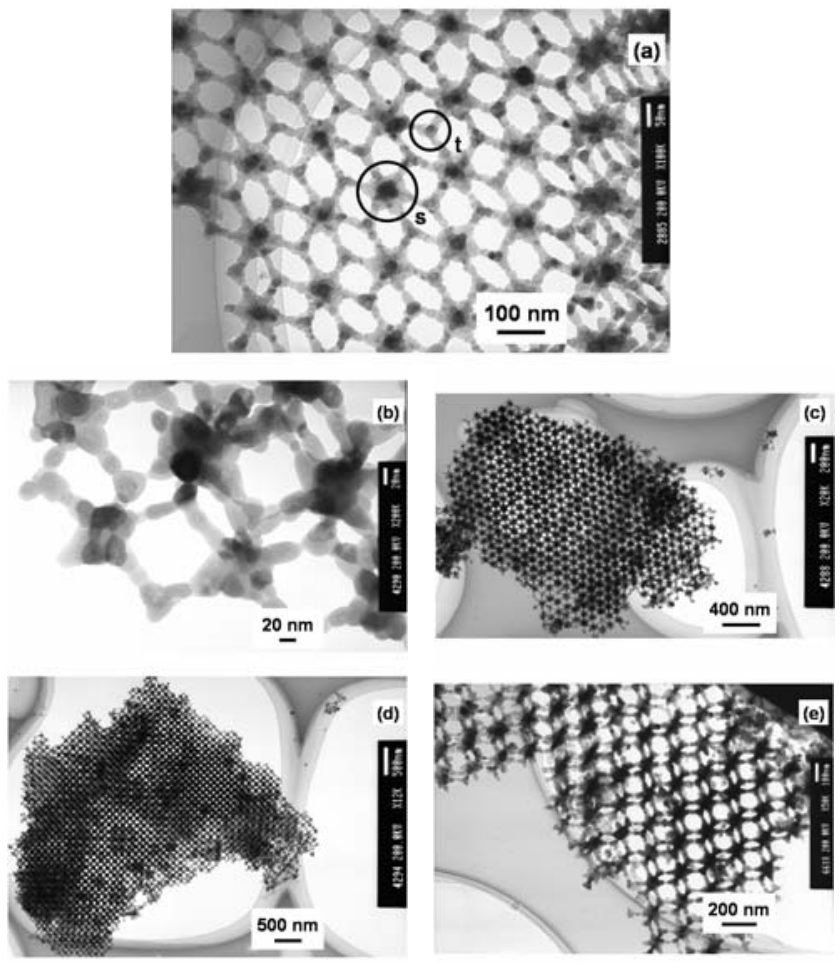

Figure 3. TEM images of the $\mathrm{ZnFe}_{2} \mathrm{O}_{4}$ material. (a) $\times 100 \mathrm{k}$, (b) $\times 200 \mathrm{k}$ (c) $\times 20 \mathrm{k}$; view towards (111) plane, (d) $\times 12 \mathrm{k}$; view towards (100) plane, and $(\mathrm{e}) \times 50 \mathrm{k}$; view towards (110) plane of the inversed opal structure. In part (a), a tetrahedral vertex and 8-coordinated square prism vertex were marked as $t$ and s, respectively.

The 3DOM structure was first confirmed by SEM. Figure 2 shows SEM images of the $\mathrm{LaFeO}_{3}$ sample as an example. For all the samples, large fractions (more than $90 \%$ of particles by SEM images) of the calcined sample were highly ordered porous structure in three-dimensions over a range of tens of micrometers (Figure S2 in ESI). Well-ordered air spheres and interconnected struts created a 3DOM material with skeleton structure and the next layer was visible in the SEM images (Figure 2).

The skeleton structure was further characterized by TEM. As seen in Figures 3a and 3b, width of struts (around $20 \mathrm{~nm}$ ) and grain sizes were similar to the crystallite size calculated by Scherrer's equation from XRD data (Table 1), indicating the grains seen in the Figure $3 \mathrm{~b}$ are the crystallites. Straight connections of the crystallites construct struts-like bonds, and agglomerations of the crystallites construct vertexes (Figure 3b). The struts connected tetragonal and square prism vertexes (marked as $\mathrm{t}$ and s, respectively, in Figure 3a) one after the other to produce inverse opal structure. Continuous ordering of the inverse opal structure was confirmed by observing the hexagonal, square, and lozenge arrangement of the (111), (100), and (110) plane, as shown in the Figures 3b-3d, respectively. In the view towards (100) plane (Figure 3c), long range order (ca. $3 \mu \mathrm{m}$ long) of the small tetragonal vertexes and big square prism vertexes one after the other in the square arrangement could be observed. Average pore diameters of $183 \pm 4$ $\left(\mathrm{ZnFe}_{2} \mathrm{O}_{4}\right), 169 \pm 2\left(\mathrm{NiFe}_{2} \mathrm{O}_{4}\right)$, and $198 \pm 3\left(\mathrm{LaFeO}_{3}\right) \mathrm{nm}$ corresponds to a distance between the centers of two neighboring air spheres were estimated by TEM images and ca. $32-42 \%$ of shrinkage from the original PMMA sphere was observed.

In conclusion, the long range ordered inverse opals of polycrystalline mixed iron oxides with skeleton structure were successfully produced for the first time. Detailed investigation of formation mechanism of the inversed opals and catalytic application of these materials are now under way.

We would like to thank Mr. K. Sugawara and Mr. Y. Nodasaka for running TEM measurements. M. S. would like to thank Northern Advancement Center for Science and Technology (NOASTEC) and "Hokkaido University Grant Program for supporting young researchers" for financial support.

\section{References and Notes}

1 a) R. C. Schroden, A. Stein, in Colloids and Colloid Assemblies, ed. by F. Caruso, Wiley-VCH Verlag GmbH and Co. KGaA: Weinheim, 2004, pp 465-493. b) A. Stein, R. C. Schroden, Current Opinion in Solid State and Materials Science, 2001, 5, 553. c) A. Stein, Microporous and Mesoporous Materials, 2001, 44-45, 227.

2 a) W. Dong, H. Bongard, B. Tesche, F. Marlow, Adv. Mater. 2002, 14, 1457. b) W. Dong, H. J. Bongard, F. Marlow, Chem. Mater. 2003, 15, 568 .

3 In the case of two spherical particles $\mathrm{A}$ and $\mathrm{B}$, the diameter ratio $(\mathrm{dA} / \mathrm{dB})$ which form the octahedron AB6 and tetrahedron AB4 and is about 0.42 and 0.23 , respectively.

4 B. T. Holland, C. F. Blanford, T. Do, A. Stein, Chem. Mater. 1999 11, 795.

5 H. Yan, C. F. Blanford, J. C. Lytle, C. B. Carter, W. H. Smyrl, A. Stein, Chem. Mater. 2001, 13, 4314 (2001).

6 C. F. Blanford, H. Yan, R. C. Schroden, M. Al-Daous, A. Stein, Adv. Mater. 2001, 13, 401.

$7 \quad$ S. Sokolov, D. Bell, A. Stein, J. Am. Ceram. Soc. 2003, 86, 1481.

8 a) S. Sokolov, A. Stein, Mater. Lett. 2003, 57, 3593. b) H. Yan, C. F. Blanford, W. H. Smyrl, A. Stein, Chem. Commun. 2000, 1477.

9 M. Sadakane, T. Asanuma, J. Kubo, W. Ueda, Chem. Mater. 2005, $17,3546$. 
NOTE The diagram is acceptable in a colored form. Publication of the colored G.A. is free of charge.

For publication, electronic data of the colored G.A. should be submitted. Preferred data format is EPS, PS, CDX, PPT, and TIFF. If the data of your G.A. is "bit-mapped image" data (not "vector data"), note that its print-resolution should be 300 dpi.

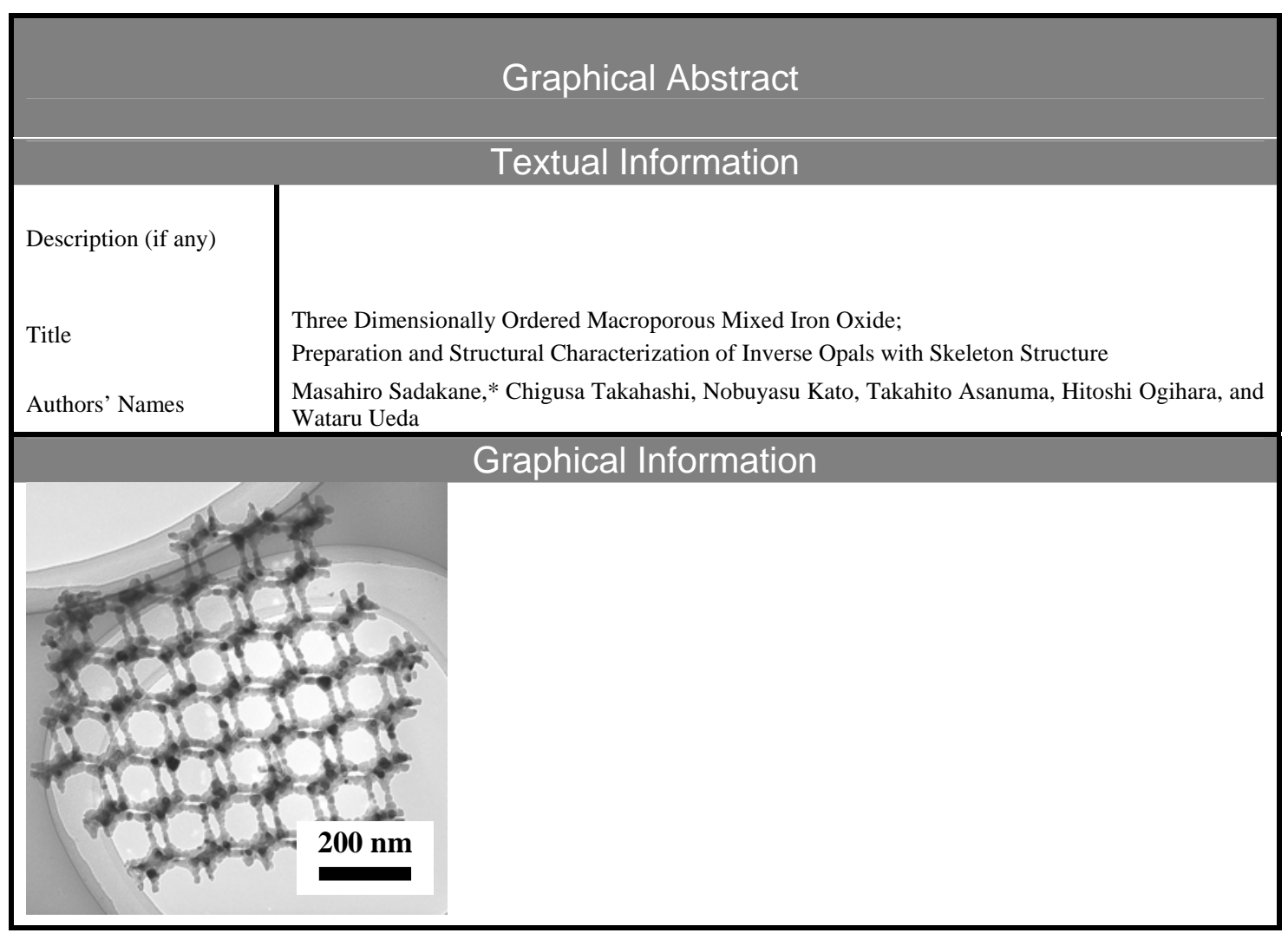

